\title{
Gestão do Conhecimento no setor público: um estudo de caso por meio do método OKA
}

Cristiano Trindade de Angelis

\section{Introdução}

A SPU faz a gestão do patrimônio imobiliário da União e direciona seus esforços para o atendimento dos interesses públicos e sociais, por meio de uma política de utilização ordenada das áreas pertencentes à União. A SPU conta com aproximadamente metade de todos os servidores do Ministério do Planejamento espalhados em um órgão central e 27 superintendências do Patrimônio da União nos estados e no Distrito Federal.

Desde 2008, a SPU está passando por uma mudança na sua arquitetura organizacional em busca de uma gestão por processos colaborativa.

Quando se tem uma gestão por processos bem definida - que diz respeito à estrutura da organização -, é compreensível que a gestão de processos - mudança contínua em busca da excelência em processos - seja facilitada e a organização seja mais receptiva à Gestão do Conhecimento $(\mathrm{GC})$ e a melhores práticas que desenvolvam a organização. 
A SPU avançou nessa direção em 2009, disponibilizando a primeira ferramenta de gestão do conhecimento: o Portal Colaborativo. Também está com vários processos em andamento, como o Sistema de Inteligência de Negócios (Business Intelligence - BI), para apoiar a tomada de decisões.

Entretanto, faz-se necessário tratar esse conhecimento gerado na SPU e formular um plano estratégico de GC, o qual necessariamente passa por uma compreensão da realidade da organização e por uma análise das iniciativas a serem executadas.

O método OKA dá suporte à elaboração de um plano de gestão do conhecimento porque aponta um bom diagnóstico da situação da organização em termos de GC, e a política de gestão do conhecimento estabelece uma visão de futuro, um elo para garantir a continuidade desse método na administração pública.

Fresneda et al. (2008) vão ao encontro disso quando afirmam que:

"O método OKA é um instrumento de diagnóstico e de apoio na elaboração do plano de GC para as organizações públicas. O método OKA tem-se demonstrado de grande utilidade para ambas as funções, assim como gerador de produto indireto, a educação dos servidores em GC, informando-os sobre o que é GC e de sua importância e benefícios para as organizações públicas" (FrESNEDA et al., 2008).

Além desta introdução e das considerações finais, este artigo apresenta mais sete itens temáticos: a parte 2 destaca a necessidade da gestão do conhecimento no setor público; a parte 3 demonstra o porquê da escolha do método OKA para fazer um diagnóstico da GC na SPU, bem como os casos de aplicação do método em organizações brasileiras; a parte 4 discorre sobre a importância de uma política de gestão do conhecimento; a parte 5 apresenta os principais referenciais teóricos; a parte 6 apresenta a metodologia utilizada para aplicação do questionário OKA; a parte 7 destaca os dois portais da SPU: o Portal Colaborativo $^{1}$ e o Portal Público ${ }^{2}$; a parte 8 apresenta os resultados da aplicação do questionário baseado no Método OKA. Por fim, são apresentadas as referências bibliográficas a que se recorreu para embasar o artigo.

\section{A necessidade da gestão do conhecimento no setor público}

Por que a administração pública deve envolver-se com GC hoje em dia? Em primeiro lugar, as organizações estão enfrentando ambientes diversos e turbulentos que exigem alta capacidade de adaptação e resolução de problemas, a fim de atender às maiores e diversas necessidades dos cidadãos. Em segundo lugar, com a revolução das TIC e a consolidação do fato de que o conhecimento é o insumo estratégico da produção na Economia do Conhecimento, as competências das pessoas envolvidas na formulação e implementação de políticas públicas devem ser tratadas com a devidas ferramentas e metodologias. Em terceiro lugar, a exigência da sociedade por serviços de qualidade e transparência na aplicação dos recursos tornou-se essencial para a administração pública que busca novos modelos para modernizar a sua gestão.

De fato, conformidade e desempenho (modelo clássico) e as melhorias trazidas pela Reforma de 1995 - em busca da administração pública gerencial, em que há 
flexibilidade, ênfase em resultados, foco no cliente e controle social - não são suficientes para que os governos lidem com questões complexas. $\mathrm{Na}$ nova economia em que vivemos - a economia do conhecimento - a resposta para os cidadãos depende cada vez mais da capacidade dos administradores de absorver o que está acontecendo no ambiente e de agir sobre o conhecimento gerado corretamente. Nesse contexto, o papel das administrações públicas no século XXI se estende para a construção da resiliência com os cidadãos e outras organizações. É preciso construir a capacidade coletiva para aprender e se adaptar ao ambiente em constante mudança. Como o ambiente está crescendo em complexidade e volatilidade. É necessário que as organizações aprendam o suficiente sobre as condições atuais e futuras do meio ambiente e usem esse conhecimento para mudar seu próprio comportamento de forma adequada (CHOO,1995). A lei de Ashby (1952) afirma que quanto maior a complexidade e incerteza, maior a quantidade de informação significativa que precisa ser processada, incorporando atividades de aprendizagem e gestão do conhecimento. A incerteza é oriunda de uma falta de compreensão do ambiente, um gap de sentido, uma construção limitada sobre o processo de busca de informações gerada por uma baixa capacidade de resolução de problemas (inteligência) e de adaptação (resiliência) às crises políticas, econômicas e sociais.

Em ambientes cada vez mais incertos, dinâmicos e complexos, torna-se cada vez mais importante para a administração pública utilizar ferramentas mais modernas de gestão, como a gestão do conhecimento. Embora se saiba que as mudanças na gestão são mais difíceis de serem implementadas no setor público e a pressão da competitividade e os incentivos para reduzir os custos são tradicionalmente menos importantes em comparação com o setor privado, a falta de estudos sobre gestão do conhecimento no setor público é um paradoxo. A OCDE (2003), em uma pesquisa intitulada "Práticas de GC nos ministérios/departamentos/agências do governo central nos países membros da OCDE”, chegou às seguintes conclusões:



- O conhecimento tornou-se fator determinante de competitividade para o setor público. Órgãos públicos cada vez mais competem uns com os outros para o uso intensivo de conhecimento.

- As empresas privadas produtoras de bens e serviços, que estão cada vez mais intensivas em capital intangível, competem diretamente com os bens e serviços 
tradicionalmente produzidos pelo setor público.

- Envelhecimento de funcionários e volume mais rápido de negócios também criam novos desafios para a preservação da memória institucional e a formação de novos funcionários.

- Cada vez mais os cidadãos exigem que os governos estejam cientes do conhecimento recém-criado, o qual é rapidamente produzido por um número cada vez maior de atores.

- Metas de políticas públicas (p. ex.: combate à exclusão) tornaram-se mais ambiciosas e complexas do que antes.

Nesse mesmo estudo, a OCDE chegou à conclusão de que o melhor meio para ter sucesso na implementação de práticas de GC é adotar alterações duráveis de comportamento que traduzam uma atmosfera de confiança e espírito de equipe, tudo assentado num ambiente organizacional e cultural relativamente estável. Para conseguir isso, as lideranças precisam atribuir valor elevado para a aprendizagem.

\section{A gestão do conhecimento e o método OKA}

Para Filho (2000), conhecimento é um conjunto formado por experiências, valores, informação e criatividade aplicada e gestão do conhecimento é uma coleção de processos que governa a criação, disseminação e utilização do conhecimento para atingir plenamente os objetivos da organização. Sveiby (2001) entende o conceito de GC como a fusão entre o gerenciamento da informação, alavancado com sistemas de informação, e o gerenciamento de pessoas, envolvendo o aprendizado e o gerenciamento das competências individuais.
O Comitê Executivo do Governo Eletrônico (Cege) entende a GC como:

Um conjunto de processos sistematizados, articulados e intencionais, capazes de incrementar a habilidade dos gestores públicos em criar, coletar, organizar, transferir e compartilhar informações e conhecimentos estratégicos que podem servir para a tomada de decisões, para a gestão de políticas públicas e para inclusão do cidadão como produtor de conhecimento coletivo. (BrasiL, 2004).

Para introduzir e sustentar as práticas de gestão do conhecimento nas organizações, Wiig (2000) sugere uma sequência de dezesseis estágios, que são blocos construtivos da GC. Nem todos esses estágios necessitam ser executados e nem mesmo executados na ordem recomendada; contudo, o segundo estágio denominado "Pesquisar e elaborar um mapa panorâmico do conhecimento" identifica a natureza, as forças e as fraquezas dos ativos de conhecimentos da organização diagnosticada.

Wiig (2000) considera que esse mapa com a situação do conhecimento é fundamental para o planejamento das estratégias de GC e priorização dos projetos e atividades, bem como para a identificação das necessidades e oportunidades específicas de GC para a organização. De acordo com o autor, o maior benefício desse diagnóstico é a geração de uma lista de iniciativas potenciais de GC, ou seja, um plano de atividades a serem implementadas (WIIG, 2000).

As ferramentas The Knowledge Management Assessment Tool (KMAT), Diagnóstico da Gestão do Conhecimento (DGC) e Organizational Knowledge Assessment (OKA) apresentam caracterís- 
ticas comuns, ou seja, o método de avaliação é não financeiro, e possuem foco em benchmarking. Os métodos com foco em benchmarking aplicam-se para avaliar os processos de gestão do conhecimento de uma organização e permitem fazer avaliações de forma comparativa com outras empresas, ou mesmo entre áreas ou grupos de uma mesma organização.

Apesar dos métodos KMAT e DGC compararem atividades de GC internamente e externamente e possuírem métodos para rápida avaliação da prática corrente, eles não medem o conhecimento verdadeiro da organização. O KMAT tem como seções: cria, identifica, coleciona, adapta, organiza, aplica, compartilha; enquanto o DGC apresenta as seguintes: obtenha, utilize, aprenda, contribua, avalie, construa e mantenha, descarte. Já o método OKA, muito mais completo e eficiente, está apoiado em três perspectivas básicas: pessoas, processos e sistemas, com cada uma delas caracterizadas por uma série de 14 "dimensões do conhecimento" que constituem o elemento-chave da ferramenta.

Essas dimensões do método OKA incorporam uma série de métricas (conforme Figura 1), escolhidas como resultado de entrevistas e pesquisa na área de gestão do conhecimento e da experiência derivada do Banco Mundial.

Em relação à dimensão Pessoas, a análise considera os elementos: cultura e incentivos, criação e identificação de conhecimento, compartilhamento de conhecimento, comunidades de prática e aprendizado. $\mathrm{Na}$ dimensão Processos consideram-se os elementos: liderança e estratégia, fluxos de conhecimento, alinhamento, operacionalização do conhecimento, métricas e monitoramento. No que diz respeito a Sistemas, são abordados os elementos: programas de gestão do conhecimento, gerência de conteúdos de conhecimento, acesso ao conhecimento e tecnologia.

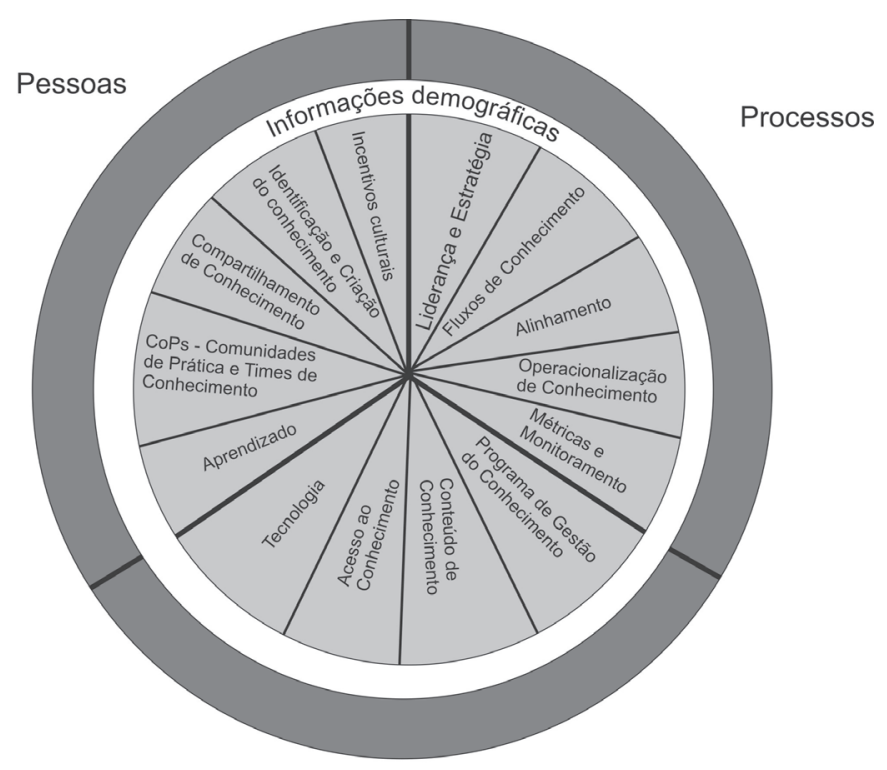

Fonte: Traduzido de Fonseca, 2006a

Sistemas

Figura 1: "Dimensões do conhecimento" do método OKA. 
Espera-se do diagrama gerado pelo método OKA, o qual demonstra visão geral e integrada da situação da GC na organização, os seguintes resultados: entendimento da situação da GC, estabelecimento de estratégias na priorização dos projetos e atividades, bem como na identificação de necessidades e oportunidades específicas no contexto da GC.

Entretanto, o método OKA possui alguns fatores dificultadores apontados por Papa(2008), como: falta de glossário de termos técnicos, tamanho do questionário, elaboração e execução do projeto de execução do OKA, educação dos envolvidos no projeto, falta de uma versão WEB, debilidade de marketing do método, dificuldade na formação da equipe de coordenadores, e poucos artigos publicados no Brasil sobre o método.

O diagnóstico da gestão do conhecimento foi realizado por meio do método OKA em diversas organizações, tais como: Ministério da Agricultura, Câmara dos Deputados, Embrapa, Banco Do Brasil, CEF, Eletronorte, e Chest. Atualmente o número de organizações internacionais que utilizaram o método OKA é de 207. Dessas organizações, 68\% são da área governamental.

Botelho (2008) afirma que, após a aplicação do método OKA na Câmara dos Deputados, foi possível visualizar com mais clareza quais os pontos fortes e os fracos da casa para continuidade da implantação de um programa de gestão do conhecimento; e afirma que tal iniciativa deveria estar vinculada à inserção da GC nos processos de trabalho da organização, como forma de dar suporte à gestão de processos, à gestão de projetos e à gestão estratégica.

Contudo, a falta de um plano de gestão do conhecimento para servir de base ao programa de GC da Câmara dos Deputados torna as ações em GC descoordenadas, segundo Botelho (2008).

\section{Importância de uma política de gestão do conhecimento para a SPU}

Não existe uma gestão da memória organizacional, tanto administrativa quanto técnica, na SPU. Esta possui quadro efetivo de servidores, mas quando o funcionário se desliga da organização, há o risco de que todo o conhecimento gerado por ele, enquanto colaborador, se perca por falta de registro prévio desse conhecimento.

Há também a questão do tempo para localizar um documento, criá-lo, ou obtêlo novamente; ou seja, há o custo de não se encontrar a informação necessária, de cuja existência se tem conhecimento, e o risco da dilatação do prazo para a conclusão das tarefas que dependem daquela informação, bem como o risco de implicações de ordem fiscal, legal e econômica, pela impossibilidade de recuperar determinadas informações.

Outros problemas merecem ser destacados: existência de grande massa de informações estratégicas não tratadas e não disseminadas aos tomadores de decisões; insuficiente colaboração intraorganizacional e interorganizacional (entre ministérios e/ou instituições públicas federais); competências individuais e coletivas não exploradas; baixa utilização de trabalho em grupo, colaborativo e virtual; dificuldade de localizar especialistas; ausência de mecanismos de compartilhamento de informações e conhecimento; falta de incentivos e mecanismos institucionais para compartilhamento e transferência de conhecimento; dificuldade de se promover o aprendizado coletivo, constituindo-se em barreira à 
capacidade de criação e inovação; necessidade de dotar a alta gerência de ferramentas de trabalho, de comunicação virtual e de informações estratégicas em tempo real.

Em pesquisa realizada com servidores públicos federais, Fresneda \& Goulart (2006) fizeram uma identificação dos problemas mais relevantes provocados pela ausência de gestão do conhecimento nas organizações públicas. seus resultados executados pelos agentes envolvidos nos processos operacionais, impactando assim os resultados alcançados.

A internalização dos processos de conhecimento na organização gera os seguintes resultados:

1) Os processos organizacionais essenciais tornaram-se líderes na aplicação da gestão do conhecimento.

2) Princípios de GC são considerados nos incentivos e avaliações pessoais.

\begin{tabular}{l|c}
\hline Problemas identificados pela ausência de GC & \% Identificações \\
\hline $\begin{array}{l}\text { Existência de grande massa de informações estratégicas não tratadas } \\
\text { e não disseminadas aos tomadores de decisões governamentais }\end{array}$ & $81 \%$ \\
\hline Competências individuais e coletivas não exploradas & $81 \%$ \\
\hline Insuficiente colaboração intraorganizacional & $50 \%$ \\
\hline Baixa utilização de trabalho em grupo, colaborativo e virtual & $50 \%$ \\
\hline $\begin{array}{l}\text { Dificuldade de promover o aprendizado coletivo, constituindo-se em } \\
\text { uma barreira à capacidade de criação e inovação }\end{array}$ & $43 \%$ \\
\hline
\end{tabular}

Todos esses desafios revelam a importância de dotar a SPU de uma Política de Gestão do Conhecimento (PGC) consistente para viabilizar a implementação de ferramentas que possam reduzir a complexidade da criação e compartilhamento do conhecimento na organização.

Um dos benefícios esperados de uma PGC é o aumento na qualidade dos processos. Sem dúvida, identificar e propagar as melhores práticas referentes à melhoria de qualidade nos processos organizacionais têm se revelado um grande benefício da adoção da gestão do conhecimento.

Firestone e McElroy ( 2005) deixam bem clara a ideia de que a GC não gerencia, cria ou integra diretamente a maioria dos resultados de conhecimento de uma organização, mas apenas impacta os processos de conhecimento, que por sua vez vão ter
3) A aplicação dos componentes de GC é disseminada em grande escala nos produtos e serviços da organização.

4) O conhecimento de feedback provido pelos clientes é incorporado nos processos da organização.

5) Lições aprendidas são introduzidas sistematicamente em novos produtos, serviços, projetos e outras atividades.

6) Comunidades de Prática são apoiadas pela organização e usadas para fomentar a criação e o compartilhamento de conhecimentos.

7) A organização possui ferramentas de TI para, sistematicamente, capturar e disseminar conhecimento.

8) Clara melhoria no comportamento dos servidores em relação ao compartilhamento de conhecimentos e nas características da organização que podem facilitar ou dificultar o trabalho. 


\section{Principais referenciais teóricos}

As vantagens da avaliação e do diagnóstico da GC para Fonseca (2006a), Hanleye Malafsky (2004), Kaplan e Norton ( 2004), Orr e Persson (2003) e Probst et al. (2002) dizem respeito a fornecer aos administradores elementos e informações para auxiliar na tomada de decisão, justificar planos e projetos, possibilitar comparações com situações anteriores dentro e fora da organização e efetuar o acompanhamento do planejamento dos assuntos relacionados com a gestão do conhecimento.

Segundo Fonseca (2006a), o método OKA propõe a realização do diagnóstico da situação da gestão do conhecimento em organização para:

a) avaliar a capacidade e o nível de preparação de uma organização na utilização de seus ativos de intelectuais;

b) ser usado como passo inicial para produzir um plano de implantação de GC nas organizações ou para avaliação de programas específicos de GC;

c) construção de um entendimento organizacional por meio de consenso;

d) conscientização proporcionadas pelos elementos e dimensões do modelo;

e) realização de comparações de resultados (benchmarking) entre unidades da mesma organização ou organizações diferentes.

Em uma de suas conclusões, na pesquisa realizada sobre gestão do conhecimento na administração pública em 2005, Batista et al. (2005) escreveram:

"Priorizar Gestão do Conhecimento é desafio para a maioria dos órgãos da administração direta. A maioria disse que o assunto é uma das cinco maiores prioridades. A maior parte das instituições se ressente da ausência de estratégia ou políticas de GC. Parte pequena das organizações respondeu que contam com estratégia na área" (BAtista et al., 2005).

A conclusão de Batista et al. (2005) corrobora com o entendimento de Fresneda e Gonçalves (2007), de que a partir de um diagnóstico inicial elaborado pelo método OKA e da análise do dados coletados seja possível cobrir essa lacuna apontada na pesquisa, isto é, definir as estratégias de GC para a organização.

O Comitê Técnico de Gestão do Conhecimento e Informação Estratégica (CT-GCIE), do Comitê Executivo do Governo Eletrônico (Cege), adotou o método OKA como ferramenta a ser utilizada pelas organizações públicas federais no diagnóstico da situação da GC e para o fornecimento de subsídios na elaboração de um plano de GC para essas organizações.

O modelo OKA foi escolhido para estudo desta pesquisa, junto à SPU, em função de outras condicionantes a saber:

a) Para Fresneda e Gonçalves (2007), como a maioria das organizações da administração pública federal (APF) não possui plano de GC e necessita de instrumento para sua elaboração, os autores entendem que o método OKA é um instrumento útil e adequado para efetuar um diagnóstico inicial em uma organização da APF e, a partir da análise dos dados coletados pela aplicação do método OKA, estabelecer as estratégias e as ações de execução, ou seja, elaborar o plano de GC da organização;

b) Batista et al. (2005) recomendam a promoção da cooperação entre empresas estatais e órgãos e entidades da administração direta, com o objetivo de disseminar práticas de gestão. Essa cooperação pode ser facilitada a partir de diagnósticos semelhantes, gerados pelo mesmo método de avaliação; 
c) O diagrama gerado pelo método OKA demonstra a situação da GC na organização e esse diagnóstico, para Wiig (2000), pode ser utilizado para inúmeros propósitos: entendimento da situação da GC, estabelecimento de estratégias na priorização dos projetos e atividades, bem como na identificação de necessidades e oportunidades específicas no contexto da gestão do conhecimento;

d) A possibilidade de repetir o diagnóstico da situação da GC, utilizando o método OKA, e poder comparar o resultado atual com resultados anteriores, é um fator importantíssimo; pois, para Sveiby (1998), uma avaliação nada significa se não for comparada a algum tipo de referencial: a outra organização ou a situações anteriores.

A gestão do conhecimento é antes de tudo o reconhecimento de que a informação e o conhecimento são ativos corporativos valiosos, que precisam ser devidamente compreendidos e gerenciados por meio de ferramentas apropriadas.

Carvalho (2003) propõe uma classificação para as ferramentas de GC, composta pelas seguintes categorias: intranets, gerenciamento eletrônico de documentos (GED), groupware, workflow, bases inteligentes de conhecimento, business intelligence, mapas de conhecimento, ferramentas de apoio à inovação, sistemas de inteligência competitiva e portais corporativos.

Segundo pesquisa realizada por Goulart (2007), na categoria de práticas relacionadas à base tecnológica e funcional de suporte à gestão do conhecimento, percebe-se que a de maior grau de implantação são os portais. Isso está ligado à necessidade de compartilhamento e disseminação de conhecimentos. As três práticas que se seguem em graus de implantação (sistemas de workflow, gestão de conteúdos e gestão eletrônica de documentos) evidenciam a necessidade de organizar e imprimir agilidade aos processos internos das organizações do governo federal.

Batista et al. (2005) definem as ferramentas de colaboração (p. ex.: portais, intranets e extranets) como: portal ou outros sistemas informatizados que capturam e difundem conhecimento e experiência entre trabalhadores/departamentos. Portal é um espaço web de integração dos

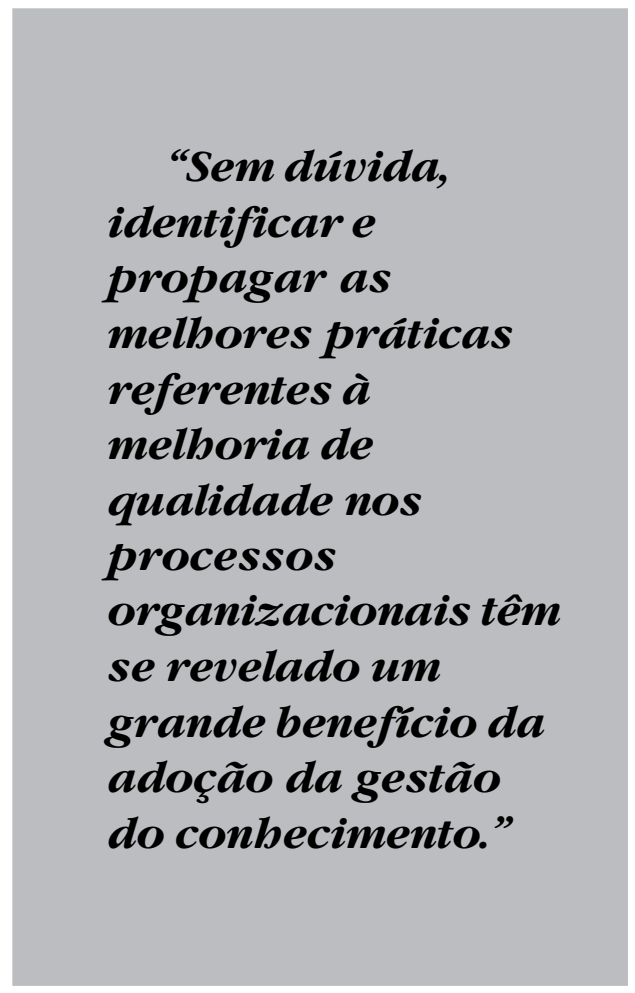

sistemas corporativos, com segurança e privacidade dos dados; pode constituir-se em verdadeiro ambiente de trabalho e repositório de conhecimento para a organização e seus colaboradores, propiciando acesso a todas as informações e às aplicações relevantes, e também servir como plataforma para comunidades de prática, redes de conhecimento e melhores 
práticas. Nos estágios mais avançados, permite customização e personalização da interface para cada um dos funcionários.

\section{Metodologia}

O questionário baseado no Método OKA, e apresentado no Anexo, foi respondido por 21 servidores, entre técnicos, gerentes, diretores do órgão central e chefes de serviço da GRPU/SC.

Consultando planilhas fornecidas pela Secretaria de Recursos Humanos do Ministério do Planejamento (SRH/MP), observa-se que, em média, $40 \%$ dos servidores da SPU estão em idade ou próximos de aposentar-se, esperando que gratificações sejam incorporadas ao salário.

Procurou-se elaborar um questionário simples, breve e direto. As 52 questões, entre as 203 perguntas contidas no questionário $\mathrm{OKA}$, foram selecionadas porque foram consideradas as mais importantes, de acordo com as especificidades do setor público e da SPU, para avaliar a capacidade e o nível de preparação de uma organização em relação à utilização adequada de seus ativos intelectuais. Ademais, em estudos anteriores, o tamanho do questionário foi apresentado como a maior dificuldade para aplicação do método.

O software SysOKA ${ }^{3}$, versão 1.02, possui as seguintes funcionalidades: cadastramento da organização e dos entrevistados; coleta das respostas das questões do método; exportação e importação de respostas; relatório - gerar gráfico tipo "radar" que tem por objetivo demonstrar graficamente a situação atual da GC da organização.

Os resultados consolidados $\mathrm{da}$ pesquisa, apresentados no item 7 , darão suporte à elaboração de um plano de GC porque apontam um bom diagnóstico da situação da SPU em termos de gestão do conhecimento.

\section{Os portais da SPU}

O Portal Colaborativo da SPU foi disponibilizado dia 11 de fevereiro de 2009. É uma ferramenta wiki capaz de disseminar, compartilhar e armazenar conhecimento. Em abril de 2009, o portal atingiu a marca de 300 usuários cadastrados. É um fato relevante considerando o pequeno intervalo de tempo de sua existência.

O Portal Colaborativo da SPU criou uma infraestrutura para o estabelecimento de "comunidades de prática", objetivando o compartilhamento de informações e experiências, o desenvolvimento de canais de comunicação entre a "linha de frente", o órgão central da SPU e as gerências regionais, além de estreitar os laços de relacionamento profissional. É um ambiente de debates e serviços relevantes à gestão do patrimônio da União, além de um repositório de arquivos compartilhados. Novos serviços têm sido agregados ao Portal, como os de chat e gerenciamento de fotos, graças aos esforços da Coordenação-Geral de Cadastro e Sistemas da SPU (CGCAS) da SPU para a evolução do portal.

A CGCAS vem trabalhando na construção de propostas de melhoria de seu atendimento de TI, de forma a dar maior rapidez e transparência. Um bom exemplo disso é a disponibilização, no portal, da prestação de contas e da pauta das reuniões. Se alguém achar que algum assunto não esta sendo colocado em pauta, pode abrir a discussão no portal. Interessante observar que o aprendizado coletivo gerado pelo portal está servindo para fazer interpretação e discussão de mérito de leis. 
O maior benefício do portal é propiciar a disseminação e compartilhamento do conhecimento por meio das melhores práticas e lições aprendidas. Contudo, a centralização com emprego de instruções normativas (IN) muito antigas e a comunicação por papel contribuíram para o uso de instrumentos diferentes para situações idênticas. São os principais gargalos que o portal, aos poucos, está solucionando.

O Portal Público da SPU deslanchou a partir dos avanços do Portal Colaborativo. Além de criar uma comunidade nesse portal e colocar à disposição dos internautas o Fale Conosco, está criando o FAC (perguntas mais frequentes), um glossário, um espaço para atendimento ao público por gerência regional e outro para sugestões de facilidades que poderiam ser inseridas no Balcão Virtual. Não obstante, confeccionou o Manual de Procedimentos ao Público junto ao Patrimônio da União, para orientar as diversas gerências regionais.

\section{Resultados}

Os pontos mais significativos das respostas do questionário, por dimensão do conhecimento, são:

\section{$I-$ Pessoas}

1) Os servidores ajudam nas mudanças dos processos organizacionais de uma forma "ad-hoc".

2) Os servidores são pouco (apenas em algumas áreas da organização) incentivados a identificar conhecimentos que possam beneficiar/melhorar processos operacionais na organização.

3) A alta gerência é pouco influente sobre a cultura organizacional.

4) Os servidores não compreendem o quanto seu papel contribui para a performance da organização.
5) A estrutura hierárquica é influente na definição dos padrões de comunicação na organização.

6) O grau de receptividade da organização em relação a sugestões dos servidores é baixo.

7) Os servidores se aconselham com muita frequência com outros servidores, buscando ter acesso a seus conhecimentos ou a seu "know-how" tácito.

8) As atividades de GC (criação do conhecimento, armazenamento, disseminação) que concorrem para os objetivos explícitos da organização são essenciais para a performance do negócio.

A política de GC deve contemplar a capacitação, principalmente da gerência média da SPU, em conceitos e ferramentas de gestão do conhecimento. A aplicação do método OKA na SPU serviu também para avaliar o grau de conscientização da organização em relação ao tema. A conscientização sobre a importância da GC não é uniforme, mesmo entre os usuários do Portal Colaborativo. Entretanto, alguns projetos-piloto estão sendo implementados, como é o caso do Portal Temático da SPU, Projeto de Gestão Eletrônica de Documentos (GED), e do Sistema de Inteligência de Negócios (Business Intelligence-BI).

Um dos fatores que dificultam a implantação efetiva da gestão do conhecimento na SPU é o alinhamento das ações de GC com seu planejamento estratégico.

\section{II - Processos}

1) A gerência média é, com pouca frequência, que normalmente inicia a mudança nos processos de negócio da organização.

2) A organização possui poucos processos organizacionais definidos em documentos ou outros formatos para leitura. 
3) A maioria dos servidores não sabe onde buscar informações sobre os processos organizacionais - estão em vários documentos espalhados pela organização, i.e., em cada unidade).

4) Os tipos de conhecimentos (internos ou externos) que são criados na organização são: conhecimento de procedimentos (derivados dos procedimentos administrativos), conhecimentos tópicos, conhecimentos práticos (derivado do know-how da organização). Os conhecimentos de processos, melhores práticas, lições aprendidas, conhecimentos sobre clientes não são adequadamente criados e disseminados.

5) A organização possui ritmo de mudança lento no que diz respeito à implementação de melhorias.

6) O grau de importância do conhecimento ou das informações nos processos de agregação de valor da organização (i.e., conversão de insumos em resultados) é muito elevado.

7) Alguns dos aspectos da organização que devem ser ajudados significativamente por atividades relativas a conhecimento (tais como compartilhamento de conhecimentos e operacionalização do conhecimento) são: satisfação dos clientes, processos operacionais e organizacionais, habilidade para modificar estratégias ou enfoques de resolução de problemas, políticas e procedimentos organizacionais.

8) Não há uma estratégia de GC claramente articulada (i. e., escrita) para a organização que não tem métricas de medição do conhecimento.

9) As áreas que devem se beneficiar mais do programa de gestão do conhecimento ou de atividades de compartilhamento de conhecimentos são: desenvolvimento de novos serviços, desenho de processos organizacionais e criação de uma estratégia de comunicação com clientes.
10) Um bom programa de GC da organização ajudaria os servidores a economizar tempo em seu trabalho e os processos organizacionais melhorariam significativamente.

A SPU está em busca de estabelecer uma relação entre a $\mathrm{GC}$ e seus objetivos organizacionais e reconhece que há alguns problemas culturais e técnicos que precisam ser superados para que as práticas de GC sejam parte integrante dos processos individuais e organizacionais.

Segundo os cinco estágios propostos por Gonçalves (2000), num espectro que vai de um modelo puramente funcional até o modelo essencialmente baseado em processos, a SPU se caracteriza como organização típica da Etapa C. Nesta etapa, embora a organização já tenha identificado seus processos e melhorado seus processos essenciais, ainda raciocina por funções. Nessas organizações, conforme aponta Gonçalves(2000), o poder ainda se concentra nas unidades verticais, que resistem fortemente à ideia de "horizontalizar" a gestão.

Contudo, a SPU avança no espectro proposto por Gonçalves (2000) e, gradativamente, passará a operar por meio de estruturas matriciais e equipes multifuncionais voltadas aos processos de negócios, que devem ser o meio integrador dos demais ativos da SPU. O passo mais importante nessa direção implica atribuir a responsabilidade pelo andamento de cada processo essencial a um "dono do processo", o que está sendo feito.

\section{IIII - Sistemas}

1) Comunidades de prática são apoiadas pela organização e usadas para fomentar a criação e o compartilhamento de conhecimentos. 
2) Os tipos de comunidades de prática que a organização possui são: organizada por tópicos ou assuntos; organizada para resolver problemas específicos; e organizada por processos ou atividades organizacionais ou tarefas de negócios.

3) São alguns dos resultados usuais das comunidades de prática na organização: conteúdos ou aconselhamentos relativos a temas operacionais da organização e conteúdos ou aconselhamentos relativos a produtos/serviços da organização; treinamento (criação ou execução); criação de conteúdos ou base de conhecimentos; serviços de assistência técnica (help desks); participação sistemática em revisões por pares/colegas ou processos similares; participação sistemática em decisões de processos organizacionais; conteúdos ou aconselhamentos relativos a temas estratégicos da organização; conteúdos ou aconselhamentos relativos a temas-nicho; conteúdos ou aconselhamentos que levem à inovação.

4) Os tipos de conteúdos que os servidores vêm buscando repetidamente: informação estratégica, políticas e procedimentos, informação setorial, dados estatísticos, inteligência de negócios e/ou dados de indicadores, pesquisa e desenvolvimento ou outros trabalhos analíticos, conteúdos sobre clientes, documentos relativos aos processos organizacionais, informação e estatísticas nacionais, pareceres dados a clientes.

5) O ambiente de software da organização não é adequado às necessidades organizacionais porque não permite uma navegação fácil (browsing) para encontrar conhecimentos/conteúdos por parte dos usuários.

As práticas de GC cujo foco central é a base tecnológica e funcional servem de suporte à gestão do conhecimento organizacional, incluindo automação da gestão da informação, aplicativos e ferramentas de tecnologia da informação (TI) para captura, difusão e colaboração. (BATISTA, 2005)

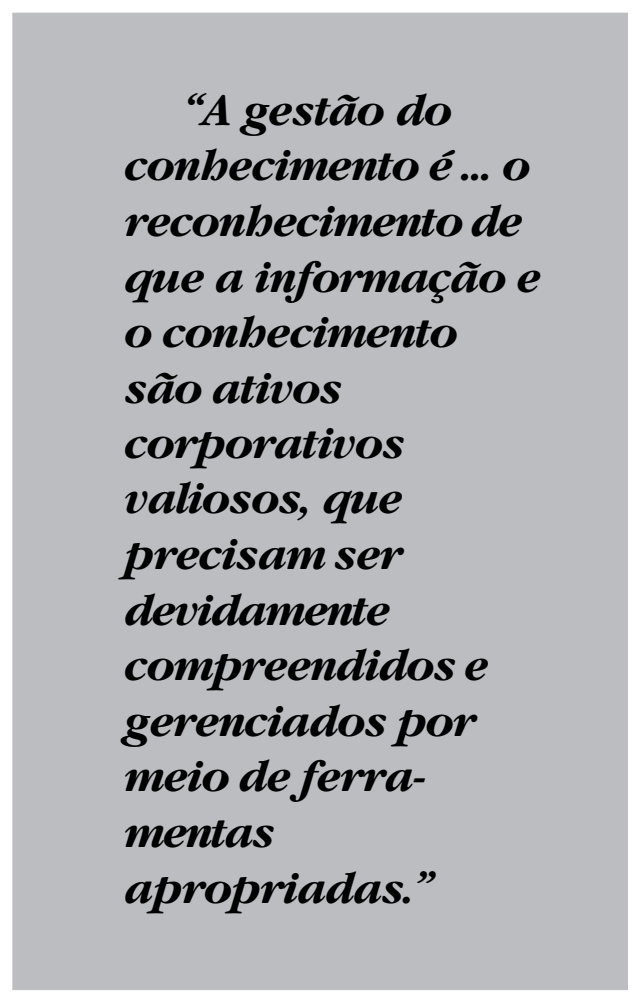

A SPU está em busca de melhorar o ambiente de software da organização, dando preferência a ferramentas tecnológicas colaborativas baseadas em software livre. A SPU reconhece que empregar práticas e ferramentas de GC traz vários benefícios, sendo que o maior deles é identificar e propagar as melhores práticas referentes à melhoria de qualidade nos processos organizacionais.

O foco, segundo Botelho (2008), deve estar no impacto das práticas de gestão de conhecimento sobre o desempenho organizacional. É importante ter em mente, 
entretanto, que existem benefícios não mensuráveis relacionados às práticas de gestão do conhecimento, tais como: informações e conhecimentos obtidos, organizados e disseminados por meio de portal corporativo; contato facilitado entre as pessoas e compartilhamento de informações e conhecimentos mediante comunidades de prática virtuais.

\section{Considerações finais}

Este artigo fez uma revisão de literatura sobre o método OKA e avaliou sua aplicação na SPU, justificando sua aplicação na elaboração de um plano estrutural de GC. Com os resultados da pesquisa podese concluir que o método OKA possibilita: i) levantar a situação da GC por dimensão do conhecimento; ii) elaborar um plano de gestão do conhecimento; iii) ser um referencial comparativo da situação da GC entre organizações; iv) estabelecer uma sistemática de avaliação do progresso da implantação do plano de gestão do conhecimento.

Em suma, o método OKA mostrouse ferramenta útil para diagnosticar e avaliar a GC nas organizações.

Para estudos futuros sugerem-se os seguintes antídotos para eliminar as fraquezas do método OKA: elaborar um glossário, convidar colegas de outras organizações públicas para compartilhar experiências, divulgação de experiências de GC via mecanismos de comunicação interna, divulgar em artigos os resultados concretos com a utilização do OKA, mostrar o caráter integrativo da GC em relação aos demais programas.

(Artigo recebido em maio de 2010. Versão final em julho de 2011).

\section{Nota}

1 Endereço eletrônico do Portal Colaborativo da SPU www.patrimoniodetodos. planejamento.gov.br

2 Endereço eletrônico do Portal Público wnw.spu.planejamento.gov.br

3 O software SysOKA, com a versão completa do questionário e as instruções de uso, pode ser obtido no endereço eletrônico http://download.tycon.com.br. Informe como usuário: tycon e senha: tycon2007.

\section{Referências bibliográficas}

Batista, F. Governo que aprende - Gestão do Conhecimento em Organiz̧ações do Executivo Federal. Texto para discussão no 1022. Brasília: IPEA, 2004.

. Gestão do Conhecimento na Administração Pública - relato completo

da pesquisa. Apresentação realizada nos Fóruns de Gestão do Conbecimento na Administração Pública, em Salvador e Recife, 2005. 
Botelho, Cássia Regina O. M. Gestão do Conhecimento para Melhoria da Gestão Pública: os caminhos da implantação da Gestão do Conhecimento na Câmara dos Deputados. 2008.

Carvalho, Rodrigo Baroni. Tecnologia da informação aplicada à gestão do conhecimento. Belo Horizonte: ComArte, 2003.

CHOO, C. W. Information management for an intelligent organization: The art of environmental scannine. Medford. NJ: Learned Information. 1995.

DHAR, Vasant; Stein, Roger. Seven methods for transforming corporate data into business intelligence. Prentice-Hall, 1997. LODI, J. B.

Firestone, J.; Mcelroy, M. Doing Knowledge Management. The Learning Organization, v. 12, n. 2, p. 189-212, abr. 2005.

Fresneda, Paulo S.V. Comitê Técnico de Gestão do Conhecimento e Informação Estratégica. Brasilia, 2005. Apresentação disponível em: http://catir.softwarepublico.gov.br. Acesso em: 04 nov. 2009.

Fresneda, Paulo Sérgio Vilches; GonçAlves, Sonia Maria Goulart; Fonseca, Ana Flavia. II Diagnóstico da Gestão do Conhecimento nas Organizações Públicas utilizando o método Organizational Knowledge Assessment (OKA). II Congresso CONSAD. Painel 20. 2008.

Fonseca, Ana Flávia. Organizational Knowledge Assessment Methodology. Washington, DC: World Bank, 2006a.

Gonçalves, Sonia M. G. Elementos básicos para a formulação de uma política de gestão do conhecimento para a administração pública federal brasileira. 2006. Dissertação (Mestrado) - Universidade Católica de Brasília, Distrito Federal.

Hanley, Susan; Malafsky, Geoffrey. A guide for measuring the value of KM investments. In: Holsapple, Clyde W. Handbook on Knowledge Management. Heidelberg, Springer, 2004 . Levantamento da interação da GC nas organizações públicas. CT- GCIE, Relatório Interno. Brasília, 2006.

Kaplan, Robert S.; NorTon, David P. Medindo a prontidão estratégica de ativos intangíveis. Harvard Business Review, p.38-48, fev. 2004.

Organization For Economic Co-operation and Development. Knowledge Management In Government: An Idea Whose Time Has Come .2003. Disponível em: <http://www.oecd.org/officialdocuments / displaydocumentpdf/?cote=GOV / PUMA/HRM(2003)1\&doclanguage=en > . Acesso em: 02 dez. 2010.

Orr, Emma; Persson, Marie. Performance indicator for measuring performance of activities in knowledge management projects. Master Thesis. University of Gothenburg: 2003.

Probst, Gilbert; RAUB, Steffen; Romhardt, Kai. Gestão do Conhecimento: Os elementos construtivos do sucesso. Porto Alegre: Editora Bookman, 2002.

SveIBY, Karl-Erik. What is knowledge management? 2001. Disponível em: <http:// www.sveiby.com/articles/KnowledgeManagement.html>. Acesso em: 31 ago. 2009. 
WiIG, Karl M. Application of Knowledge Management in Public Administration. USA, 1999.

. Introducing Knowledge management into the enterprise. In: LIEBOwITZ, Jaz. Knowledge management handbook. USA, CRC press LLC, 2000. 


\section{Apêndice}

\section{Questionário para iniciar a política de gestão do conhecimento para administração pública federal na SPU:}

Fonte: Método de Avaliação do Conhecimento Organizacional (Organizational Knowledge Assessment OKA), elaborado pelo World Bank Institute (WBI), do Banco Mundial.

Proponente: Cristiano de Angelis - Analista de Planejamento

\section{Pessoas}

1) Qual proporção da força de trabalho da empresa (servidores e consultores externos) você estima que possuem funções cuja atividade primária lida com trabalho baseado em conhecimento, não manual e rotineiro?

1. Menos que $5 \%$

2. Igual ou mais que $5 \%$ e menos que $25 \%$

3. Igual ou mais que $25 \%$ e menos que $50 \%$

4. Igual ou mais que $50 \%$ e menos que $75 \%$

5. Igual ou mais que $75 \%$ e menos que $85 \%$

6. Igual ou mais que $85 \%$

2) Qual dos itens abaixo melhor caracteriza o papel que o servidor comum desempenha na definição dos processos organizacionais?

1. Eles ajudam nas mudanças dos processos organizacionais de uma forma "ad-hoc".

2. Eles participam nas revisões sistemáticas dos processos organizacionais.

3. Eles não participam porque os processos organizacionais são definidos de cima para baixo.

3) Qual é o nível de influência da alta gerência sobre a cultura organizacional?

1. Muito influente

2. Influente

3. Pouco Influente

4. Pouquíssimo influente

5. Nada influente 
4) Em geral, você acredita que os servidores compreendem o quanto seu papel contribui para a performance da empresa?

1. Sim

2. Não

3. Não sei.

5) Qual é o nível de influência da estrutura hierárquica na definição dos padrões de comunicação na organização?

1. Muito influente

2. Influente

3. Pouco Influente

4. Pouquíssimo influente

5. Não é influente.

6) Como você caracteriza a estratégia de comunicação da alta gerência para os servidores?

1. Muito aberta

2. Aberta

3. Um pouco aberta

4. Não existe muita comunicação.

5. Fechada

7) Com que frequência a alta gerência se comunica com os servidores?

1. Muito alta

2. Alta

3. Média

4. Baixa

5. Muito baixa

8) Qual o grau de receptividade que a organização parece ter em relação a sugestões dos servidores?

1. Muito receptiva

2. Receptiva

3. Pouco receptiva

4. Pouquíssimo receptiva

5. Não receptiva.

9) A organização oferece treinamentos específicos visando auxiliar os servidores na adaptação em novas tarefas ou em novas condições de trabalho (treinamento para desenvolvimento de novas habilidades)?

1. Sim

2. Não

3. Não sei. 
10) Os servidores são incentivados a identificar conhecimentos que possam beneficiar/melhorar processos operacionais na organização?

1. Sim

2. Um pouco (apenas em algumas áreas da organização)

3. Não

4. Não sei.

11) Performance é função de vários fatores. Qual das seguintes respostas melhor representa os três elementos que mais influenciam a performance dos servidores?

1. Motivação, ambiente organizacional, habilidades

2. Conhecimento, habilidades, competências técnicas

3. Especificação do posto de trabalho (job design), habilidades, objetivos

4. Motivação, especificação do posto de trabalho, competências

5. Medo, aversão ao risco, resistência a mudanças

6. Falta de motivação, dificuldade de crescimento no ambiente organizacional, medo

\section{Sistemas}

1) Como você classifica o nível de comunicação realizado por meio de sistemas "on-line" (tais como mensagens eletrônicas, mensagens instantâneas e espaços virtuais de trabalho) na organização?

1. Muito alto

2. Alto

3. Médio

4. Baixo

5. Muito baixo

2) A organização possui uma arquitetura de informação corporativa?

Uma arquitetura de informação corporativa é um sistema esquemático que descreve os fluxos de informação entre os processos e os sistemas de TI na organização.

1. Sim

2. Não

3. Não sei.

3) Quais dos seguintes mecanismos a organização possui que permitem aos servidores compartilharem conhecimento tácito?

1. Discussões eletrônicas

2. Salas de "chats"

3. Quadros de avisos virtuais

4. Espaços virtuais

5. Fóruns eletrônicos

6. Blogs

7. Intranet 
8. Participação dos servidores em eventos presenciais (conferências, seminários, palestras etc)

9. Treinamentos ou oficinas

10.Outros.Indicar:

4) A organização possui registros ou arquivos visando criar uma memória corporativa (i.e., lições e experiências aprendidas pelos membros da equipe)?

1. Sim

2. Não

3. Não sei.

5) Qual é a importância da recuperação de informação (de sítios da internet, bases de dados, sistemas da empresa, ou outros sistemas de recuperação eletrônica da informação) para que a maioria dos servidores realize suas tarefas diárias?

1. Muito importante

2. Importante

3. Pouco importante

4. Pouquíssimo importante

5. Nada importante

6) A organização utiliza equipes/comitês regularmente para resolver problemas?

1. Sim

2. Não

7) Quais dos seguintes tipos de equipe existem na organização?

1. Comunidades de prática

2. Equipes virtuais

3. Grupos de trabalho

4. Redes de pessoas por processos ou funções

5. Equipes centradas nos clientes

6. Outras. Especificar:

8) A organização possui comunidades de prática?

1. Sim

2. Não

3. Não sei.

9) Como as comunidades de prática são criadas na organização?

1. Por um processo formal dirigido pela gerência

2. Por um processo formal iniciado por servidores

3. Informalmente por servidores da organização

4. Outras. Especificar:

5. Não sei. 
10) Que tipos de comunidades de prática a organização possui?

1. Organizada por tópicos ou assuntos

2. Organizada para resolver problemas específicos

3. Organizada por processos ou atividades organizacionais ou tarefas de negócios

4. Outros.Indicar.

5. Não sei.

6. Nenhuma das anteriores

11) Quantas comunidades de prática distintas e identificáveis a organização possui? Nenhuma

$1-5$

6-20

$21-50$

$51-100$

101 ou mais

12) Alguma das comunidades de prática da organização possui conexões ou interage com grupos externos?

1. Sim

2. Não

3. Não sei.

13) Qual dos itens abaixo caracteriza a estrutura das comunidades de prática da organização?

1. Regras e procedimentos

2. Processos de retroalimentação (feedback)

3. Listas de membros disponíveis

4. Líderes de grupos designados

5. Reuniões regulares

6. Meios eletrônicos para compartilhamento de informações (espaço virtual na rede, base de conhecimentos, sítio na internet)

7. Outros. Especificar.

14) Quais dos itens abaixo são alguns dos resultados usuais das comunidades de prática na organização?

1. Treinamento (criação ou execução)

2. Criação de conteúdos ou base de conhecimentos

3. Serviços de assistência técnica (Help Deskes)

4. Participação sistemática em revisões por pares/colegas ou processos similares

5. Participação sistemática em decisões de processos organizacionais

6. Conteúdos ou aconselhamentos relativos a temas estratégicos da organização

7. Conteúdos ou aconselhamentos relativos a temas operacionais da organização

8. Conteúdos ou aconselhamentos relativos a temas nicho 
9. Conteúdos ou aconselhamentos relativos a produtos/serviços da organização

10. Conteúdos ou aconselhamentos que levem à inovação.

11. Outros:

15) Que tipos de conteúdos são administrados pelos sistemas ou repositórios de conteúdos da organização?

1. Informação estratégica

2. Políticas e procedimentos

3. Informação setorial

4. Dados estatísticos

5. Inteligência competitiva e/ou dados de indicadores

6. Pesquisa e desenvolvimento ou outros trabalhos analíticos

7. Conteúdos relativos aos clientes

8. Documentos relativos a processos organizacionais

9. Informações e estatísticas nacionais

10. Recomendações feitas a clientes

11. Informação do tipo avaliativa

12. Outras. Especificar.

13. A organização não possui sistemas/repositórios de conteúdos.

16) De qual forma mais abrangente a organização organiza conteúdos?

1. Organizado por processo

2. Por área tópico, tal como arrecadação

4. Por projeto ou atividade

5. Outro. Especificar:

6. Nenhuma das anteriores

17) Qual dos tipos de conteúdos de conhecimento a organização possui?

1. Documentos oficiais

2. Publicações

3. Material publicado na web

4. Noticiários, boletins

5. Videoconferências, fóruns eletrônicos, discussões eletrônicas

6. Novidades knowledge nuggets

7. Dados estatísticos

8. Dados de sistemas de informação geográficos

9. Informações e publicações externas

10. Informações de pessoas, diretórios

11. Conhecimento sobre processos internos da organização

12. Conhecimento sobre parceiros

13. Informação do tipo "saber-fazer" (know-bow)

14. Informações sobre habilidades

15. Outro. Indicar: 


\section{Processos}

1) Qual o grau de importância do conhecimento ou das informações nos processos de agregação de valor da organização (i.e., conversão de insumos em resultados)?

1. Muito importante

2. Importante

3. Pouco importante

4. Pouquíssimo importante

5. Não importante

2) Em que medida a organização apoia a interação social que permita o compartilhamento de conhecimento tácito entre pessoas?

1. Apoia muito.

2. Apoia.

3. Apoia pouco.

4. Apoia pouquíssimo.

5. Não apoia.

3) Como a informação ou o conhecimento é disseminado pela organização aos seus servidores?

1. Pela intranet

2. Por um sítio público da internet

3. Por meio de um boletim (eletrônico ou físico)

4. Por meio de reuniões realizadas pela alta gerência

5. Por meio de eventos sociais informais

6. Por mensagem eletrônica (e-mail)

7. Por meio de reuniões de divisão/unidade/departamento

8. Alguma outra forma. Indicar:

9. Não é disseminada.

4) A organização possui um sistema de gestão do conhecimento?

Sistema de gestão do conhecimento é o conjunto de práticas distintas e interligadas visando melhorar o desempenho organizacional por meio de produção, retenção, disseminação, compartilhamento e aplicação do conhecimento dentro das organizações e na relação dessas com o mundo exterior.

1. Sim

2. Não

3. Não sei.

5) Em que grau os sistemas de gestão do conhecimento estão integrados no fluxo de trabalho da organização com vistas a criar novos conhecimentos? Exemplos de sistemas de GC: Fóruns presenciais/listas de discussão, comunidades de prática, melhores práticas, benchmarking, memória organizacional, mapeamento do conhecimento, gestão 
por competências, banco de competências organizacionais e individuais, gestão do capital intelectual, portais/intranets/extranets, sistemas de workflow, gestão de conteúdo, gestão eletrônica de documentos.

( ) alto ( ) médio ( ) baixo

6) Quais das seguintes frases melhor descrevem o grau em que os processos de conhecimento são internalizados na organização:

1. Os processos organizacionais essenciais tornaram-se líderes na aplicação da gestão do conhecimento;

2. Princípios de GC são considerados nos incentivos e avaliações pessoais;

3. A aplicação dos componentes de GC está disseminada em grande escala nos produtos e serviços da organização;

4. O conhecimento de feedback provido pelos clientes é incorporado nos processos da organização;

5. Lições aprendidas são introduzidas sistematicamente em novos produtos, serviços, projetos e outras atividades;

6. Comunidades de prática são apoiadas pela organização e usadas para fomentar a criação e o compartilhamento de conhecimentos

7. A organização possui ferramentas de TI para, sistematicamente, capturar e disseminar conhecimento;

8. Houve clara melhoria no comportamento dos servidores em relação ao compartilhamento de conhecimentos;

9. Os agentes de GC têm conseguido atuar na organização como um todo e participam dos encontros estratégicos e dos exercícios de planejamento organizacionais;

10. Nenhuma das anteriores.

7) Quais tipos de conhecimentos (internos ou externos) são criados na organização?

Conhecimentos de processos

Conhecimento de procedimentos (derivados dos procedimentos administrativos)

Conhecimentos tópicos

Conhecimentos práticos (derivado do know-how da organização)

Melhores práticas

Lições aprendidas

Conhecimentos sobre clientes

Outro tipo. Indicar:

Nenhuma das anteriores

8) Qual dos tipos de conhecimentos e/ou informações abaixo são capturados por sua organização?

1. Lições aprendidas

2. Documentos sobre projetos e produtos

3. Mensagens eletrônicas formais

4. Listas de especialistas 
5. Resultados de grupos de discussões ou discussões eletrônicas

6. Informações sobre clientes

7. Dados relativos ao desempenho dos servidores

8. Projetos de pesquisa

9. Intercâmbio de vídeo ou áudio

Outros. Especificar:

9) Quais dos seguintes itens refletem as principais formas de armazenamento de conhecimentos da organização?

1. Intranet

2. Extranet

3. Internet

4. Bases de dados (inclusive sistemas de gerenciamento de documentos, inteligência em negócios, sistemas de Planejamento de Recursos Empresariais (ERP), sistemas de gestão de projetos etc.)

5. Arquivos/documentos em uma pasta pública hierarquizada (servidor de arquivos ou servidor FTP - Protocolo de Transferência de Arquivos)

6. Unidades de disco em rede (arquivos/documentos armazenados, disponíveis para o público - servidor de arquivos ou servidor FTP)

7. Arquivos pessoais de servidores

8. Arquivos de e-mail

9. Outros. Especificar:

10) Como o conhecimento implícito/tácito é disseminado?

1. Apresentações formais

2. Almoços informais

3. Reuniões de unidades organizacionais

4. Conversas informais entre servidores

5. E-mails

6. Videoconferências

7. Audioconferências

8. Telefone

9. Revisões de pares (peer review)

10. Fóruns

11. Conferências

12. Programas de mentoring

13. Revisões operacionais de qualidade

14. Revisões de desempenho formal

15. Outras. Especificar.

11) Qual é o nível de efetividade dos sistemas de gestão do conhecimento em conectar as pessoas com os sistemas de informação?

1. Muito efetivo

2. Efetivo

3. Pouco efetivo 
4. Pouquíssimo efetivo

5. Não efetivo.

12) Quais dos seguintes tipos de conhecimentos explícitos a organização compartilha?

1. Melhores práticas e lições aprendidas

2. Documentos e publicações institucionais

3. Informações sobre especialistas

4. Diretório corporativo de pessoas

5. Dados de entrevistas e de brainstorming

6. Vídeos de eventos e de entrevistas

7. Decisões

8. Dados de clientes

9. Dados de mercado

10. Outros. Especificar:

13) Quais são as fontes que a organização utiliza para identificar os conhecimentos que ela deseja coletar?

1. Pesquisa pela internet

2. Pesquisa usando bases de informações (interno e externo)

3. Da experiência de servidores

4. Da experiência de parceiros

5. Outras. Especificar.

6. Nenhuma das anteriores

14) Quais fontes de informação abaixo são obtidas e usadas nos processos decisórios da organização?

1. Melhores práticas

2. Comparação (benchmarking) com concorrentes

3. Feedback de clientes

4. Feedback de servidores

5. Pesquisa e inteligência competitiva

6. Lições aprendidas

Outros. Indicar:

15) Quais tipos de métricas operacionais ou ferramentas de medição a organização usa para determinar o valor do conhecimento organizacional?

1. Balanced Scorecard

2. Retorno de Investimento - ROI

3. Custo da qualidade

4. Pesquisa de satisfação dos clientes

5. Pesquisas de satisfação dos servidores

6. Um processo sistemático de avaliação de pessoal

7. Programa de qualidade total 
8. Processos/funções relativos à auditoria

9. Processos/funções de avaliação operacional

10. Modelo de Maturidade de Processos (CMM)

11. Índice de Capital Humano

12. Revisões de manutenção (de qualquer tipo)

13. Outros. Indicar:

14. A organização não tem/ ou não usa métricas de medição do conhecimento.

16) Quais são alguns dos aspectos da organização que devem ser ajustados significativamente por atividades relativas a conhecimento (tais como compartilhamento de conhecimentos e operacionalização do conhecimento)?

1. Satisfação dos clientes

2. Processos operacionais organizacionais

3. Produtividade organizacional

4. Habilidade para modificar estratégias ou enfoques de resolução de problemas

5. Políticas e procedimentos organizacionais

6. Outros. Especifique:

17) Há uma estratégia de GC claramente articulada (i.e., escrita) para a organização?

1. Sim

2. Não

3. Não sei.

18) Como você caracterizaria a liderança das atividades de gestão do conhecimento na organização?

1. Realizada basicamente pelo nível da alta gerência

2. Balanceada entre a alta gerência e as gerências médias e inferiores

3. Realizada basicamente pelos níveis de gerência média e inferior

19) De que modo as atividades de GC (criação do conhecimento, armazenamento, disseminação) concorrem para os objetivos explícitos da organização?

1. Essencial para a performance do negócio

2. Importante para a obtenção de vantagem competitiva

3. Importante para levar à inovação

4. Defasado ou não necessário

5. Nenhuma das anteriores. Explicite qual:

6. Não sei.

20) Quais áreas devem se beneficiar mais do programa de GC ou de atividades de compartilhamento de conhecimentos?

1. Desenvolvimento de novos produtos

2. Desenvolvimento de novos serviços

4. Desenho de processos organizacionais 
5. Criação de uma estratégia de comunicação com clientes

6. Outro. Especificar:

21) Você acha que os processos organizacionais vão melhorar significativamente como resultado de um bom programa de GC da organização?

1. Sim

2. Não

3. Não sei.

22) Um bom programa de GC ajudaria os servidores a economizar tempo em seu trabalho?

1. Sim

2. Não

3. Não sei.

23) Um bom programa de GC aumenta o valor das oportunidades de desenvolvimento profissional para os servidores?

1. Sim

2. Não

3. Não sei.

24) Os seguintes grupos estão cientes das lacunas de conhecimento que devem ser preenchidas para que a organização atinja seus objetivos?

\begin{tabular}{|l|c|c|c|}
\hline & Sim & Não & Não sei. \\
\hline Servidores & $\square$ & $\square$ & $\square$ \\
\hline Gerência média & $\square$ & $\square$ & $\square$ \\
\hline Alta gerência & $\square$ & $\square$ & $\square$ \\
\hline
\end{tabular}




\section{Resumo-Resumen-Abstract}

\section{Gestão do Conhecimento no setor público: um estudo de caso por meio do método OKA Cristiano Trindade de Angelis}

Dentre os modelos de avaliação e diagnóstico de gestão do conhecimento pesquisados na literatura, selecionou-se o método de Avaliação do Conhecimento Organizacional (Organizational Knowledge Assessment - OKA) elaborado pelo World Bank Institute (WBI), do Banco Mundial, como um modelo com capacidade de avaliar e diagnosticar a situação da Gestão do Conhecimento (GC) em uma organização. O método OKA foi concebido para avaliar a capacidade e o nível de preparação de uma organização na utilização adequada de seus ativos intelectuais. O artigo propõe realizar um diagnóstico da gestão do conhecimento na Secretaria do Patrimônio da União (SPU), pertencente ao Ministério do Planejamento. Durante a pesquisa na SPU usando o método OKA surgiu a necessidade de formular uma política de gestão do conhecimento, isto é, um plano estratégico de GC. A pesquisa concluiu que o método OKA é uma ferramenta útil para diagnosticar e avaliar a GC na SPU e na concepção de um plano estratégico de GC, definidor de ações, práticas de apoio e orientações às políticas e processos de conhecimento da organização.

Palavras-chave: Conhecimento; gestão do conhecimento; setor público; método OKA

\section{Gestión del conocimiento en el sector público: un estudio de caso a través del método OKA Cristiano Trindade de Angelis}

Entre los modelos de evaluación y diagnóstico de la gestión del conocimiento en la literatura examinada, se selecionó el método de Evaluación del Conocimiento Organizacional (Organizational Knowledge Assessment - OKA) preparado por el World Bank Institute (WBI), del Banco Mundial, como un modelo capaz de evaluar y diagnosticar la situación de la Gestión del Conocimiento (GC) en una organización. El método OKA fue diseñado para evaluar la capacidad y nivel de preparación de una organización en el uso adecuado de sus activos de propiedad intelectual. El artículo se propone realizar un diagnóstico de la gestión del conocimiento en la Secretaría de Patrimonio de la Unión (SPU), Ministerio de Planificación. Durante la investigación sobre la SPU con el método OKA surgió la necesidad de formular una política de gestión del conocimiento, es decir, un plan estratégico para la GC. La investigación concluyó que el método OKA es una herramienta completa y útil para diagnosticar y evaluar la GC en la SPU y el diseño de un plan estratégico para la GC, la definición de acciones, prácticas y orientación para apoyar las políticas y procesos para el conocimiento de la organización.

Palabras clave: Conocimiento; gestión del conocimiento; sector público; método OKA.

\section{Knowledge Management in the public sector: a case study under the OKA method Cristiano Trindade de Angelis}

Among the models of assessment and diagnosis of Knowledge Management in the literature surveyed was selected the method " Organizational Knowledge Assessment (OKA)" prepared by the World Bank Institute (WBI), World Bank, as a model capable of assess and diagnose the situation of Knowledge Management (KM) in an organization. The method OKA was designed to assess the capacity and level of preparedness of an organization in proper use of their intellectual assets. The article proposes to conduct a diagnosis of Knowledge Management at the Secretary of the Federal Heritage of Ministry of Planning. During the research on SPU using the OKA came the need to formulate a policy of Knowledge Management, ie, a Strategic Plan of KM. The research 
concludes that the method OKA is a complete and useful tool to diagnose and assess the KM in the SPU and the design of a Strategic Plan for KM, defining actions, practical support and guidance to policy and knowledge processes of the organization.

Keywords: Knowledge; Knowledge Management; Public Sector; OKA method.

Cristiano Trindade de Angelis

Doutorando em Engenharia de Produção pela Universitá Degli Studi di Padova (Unipd), na Itália. Atualmente é Analista do Ministério do Planejamento.

Contato: angelis.cristiano@gmail.com 